\title{
An Expert System for Life Prediction of Woven-roving GFRE Closed end Thick Tube Subjected to Combined Bending Moments and Internal hydrostatic Pressure Using (ANN)
}

\author{
M.N. Abouelwafa, Hassan El-Gamal, Yasser S. M., Wael A. Al-Tabey \\ Department of Mechanical Engineering, \\ Faculty of Engineering, Alexandria University, \\ Alexandria (21544), Egypt
}

\begin{abstract}
As the study of fatigue failure of composite materials needs a large number of experiments as well as long time, so there is a need for new computational technique to expand the spectrum of the results and to save time. The present work represents a new technique to predict the fatigue life of Woven Roving Glass Fiber Reinforced Epoxy (GFRE) subjected to combined completely reversed bending moments and internal hydrostatic pressure, at different pressure ratios $\left(P_{r}\right), P_{r}=0,0.25,0.5,0.75$ (i.e. pressures amounting to $0 \%, 25 \%, 50 \%$ and $75 \%$ of the burst pressure). Two fiber orientations, $\left[0^{\circ}, \mathbf{9 0}^{\circ}\right]_{3 \mathrm{~s}}$ and $\left[ \pm 45^{\circ}\right]_{3 \mathrm{~s}}$ are considered. Two neural network structures, feed-forward (FFNN) and generalized regression (GRNN), are applied, trained and tested. The groups of data considered, are the maximum stress and the Pressure ratio with the fiber orientation. On the other hand, more accurate prediction method is obtained by using a useful expert system which is designed to aid the designer to decide whether his suggested data for the composite structure is suitable or not. In this expert system a neural network is designed to consider the design data as input and to get yes or no as output. The results show improvement when using the one input life $(N)$ of the maximum stress $\left(\sigma_{\max }\right)$ and the pressure ratio $\left(P_{r}\right)$. Also the feed-forward neural network shows better results than that given by the generalized regression network. The designed expert system helped the designer with a100\% correct conclusions about his decision of the combination of the proposed data.
\end{abstract}

Keywords: NN predication, Fatigue of composites, Expert systems, Neural network modeling

\section{INTRODUCTION}

The study of the fatigue phenomena is more complex for composite materials [1] than for the conventional ones. This is due to inhomogenity of composites, as they contain numerous internal boundaries. These boundaries separate the constituent materials that have different responses and different resistances to the long-term applications of external influences.

A wide literature review showed that the fatigue behavior of composite materials is dependent on many factors. However, it is impossible to include all of them in a single laboratory test.

Modeling of these factors effects involves the development of a mathematical tool derived from experimental data. Once the model is established it can significantly reduce the experimental work involved in designing new polymer composite. For this reason, Artificial Neural Networks (ANN) has recently been introduced into the field of polymer composites [2].

Lee et al. [3] carried out an ANN predication on the fatigue life of some carbon/glass fiber reinforced plastic (CFRP/GFRP) laminates. Three fatigue parameters (peak stress, minimum stress and probability of failure) as well as four mono- tonic mechanical properties (tensile strength, compression strength, tensile failure strain and tensile modulus) were selected as the ANN inputs, which were applied to predict the fatigue life of the composite as the output. They concluded that the ANN's can be trained at least to model constant - stress fatigue behavior as well as other current life predica-tion methods and can provide accurate representations of the stress, stress ratio and median life for carbon fiber composites from a quite small experimental dataset.

The ANN predictive results of Aymerich and Serra [4] confirmed that the properties of the basic element (lamina) and their orientation within the laminate strongly affect the fatigue performance of composite lami-nates. It is concluded that an ANN is a very attractive approach to predict fatigue life of laminate composites, although a larger data- set is needed when increasing the number of laminate parameters.

Al-Assaf and El-Kadi [4] applied the ANN approach to predict the fatigue life of unidirectional glass fiber/epoxy composite. Only the stress ratio (R = minimum stress/ maximum stress), the maximum stress and the fiber orientation angle were used as the ANN input, and the output was the number of cycles 
to fatigue failure. In order to improve the predictive accuracy, other types of ANN's were considered in a later publication [5].

El-Kadi and Al-Assaf [6] used the strain energy to be the input to the artificial neural network to predict the fatigue life of glass fiber/epoxy composites.

Choi S.W. et al. [7] studied the fatigue damage predication in notched composite laminates using an artificial network. The ANN model was developed to describe the split growth in notched AS4/3501-6 graphite/ epoxy quasi- isotropic laminates under constant amplitude fatigue. The ANN model is found to work well.

In the present study, a new technique to simulate and predict the fatigue life of woven- roving glass fiber reinforcement epoxy (GFRE) composite material subjected to combined internal pressure and completely reversed bending with variable pressure ratios $\left(P_{r}=0,0.25,0.5,0.75\right)$ at two fiber orientations, $\left[0,90^{\circ}\right]_{3 \mathrm{~s}}$ and $\left[ \pm 45^{\circ}\right]_{3 \mathrm{~s}}$.

The neural network is used in this study and compared to the experimental data [8]. Two neural network structures, feed-forward and generalized regression, are applied, trained and tested. An expert system is designed to predict whether the quality of the used composite will meet the needed requirements of stress and number of cycles to failure whatever the orientation angle is.

\section{EXPERIMENTAL WORK}

The dataset used in this work is adapted from reference [8]. The tests were conducted on thick closed end tubular specimens under four-point pressure configuration. The loading system produces a bending moment in the form of sine wave with constant stress ratio, the minimum to the maximum stresses equal to (-1). At each pressure ratio both the maximum stress and the number of cycles to failure $\mathrm{N}$ were measured. Two fiber orientations; $\left[0,90^{\circ}\right]_{3 \mathrm{~s}}$ and $\left[ \pm 45^{\circ}\right]_{3 s}$ are tested for each $P_{r}$. The test results are fitted to give the following equation.

$\sigma_{\max }=\mathrm{aN}^{\mathrm{b}}$

The values of $a$ and $b$ for both fiber orientations are displayed in Table (1) and Table (2).

\section{STRESS STATE}

Specimens are subjected to combined bending fatigue moments and internal Pressure with different pressure values. Being closed end cylindrical in shape, their global stress $\left(\sigma_{x}\right),\left(\sigma_{y}\right)$ and $\left(\tau_{x y}\right)$ may be found from the following equation:

$\sigma_{x}=\frac{M y}{I}+\sigma_{l}, \sigma_{y}=\sigma_{H}$ and $\tau_{x y}=0$

Where:

$M$ : applied bending moment $\left(M=M_{m}+\right.$ $\left.M_{a} \sin (\omega t)\right)$.

$M_{m}$ and $M_{a}$ : mean and amplitude bending moments, respectively.

$I$ : second moment of area for tube; $I=$ $(\pi / 64)\left(d_{o}^{4}-d_{i}^{4}\right)$.

$\sigma_{l}$ : Longitudinal stress (MPa), $\quad\left(\sigma_{l}=\right.$ $\left.P_{i} r_{i}^{2} / r_{o}^{2}-r_{i}^{2}\right)$ for thick tube.

$\sigma_{H}$ : Hoop stress (MPa),

$\left(\sigma_{H}=\left(P_{i} r_{i}^{2} / r_{o}^{2}-r_{i}^{2}\right)\left(1+r_{o}^{2} / r^{2}\right)\right)$ for

thick tube.

$P_{i}$ : Internal pressure.

$d_{o}$ and $d_{i}$ : Outer and inner diameters of the specimen, respectively and $r=d_{i} / 2$.

The $\left[0^{\circ}, 90^{\circ}\right]_{3 s}$ specimens had a pure local stress state, $\sigma_{1}=\sigma_{x}, \sigma_{2}=\sigma_{y}$ and $\sigma_{6}=0$, while the $\left[ \pm 45^{\circ}\right]_{3 s}$ specimens had 1 ocal stress state, $\sigma_{1}=\sigma_{2}=$ $(1 / 2)\left(\sigma_{x}+\sigma_{y}\right)$ and $\sigma_{6}=(1 / 2)\left(\sigma_{x}-\sigma_{y}\right)$.

TTABLE I.FATIGUE CONSTANTS (A) AND (B) FOR $\left[0^{\circ}, 90^{\circ}\right]_{3 \mathrm{~s}}$ SPECIMENS

\begin{tabular}{|c|c|c|c|}
\hline $\begin{array}{c}\text { Pressure ratio } \\
\left(\boldsymbol{P}_{\boldsymbol{r}}\right)\end{array}$ & \multicolumn{3}{|c|}{$\left[\mathbf{0 , 9 0}^{\circ} \boldsymbol{3}_{\mathbf{s}}\right.$} \\
\cline { 2 - 4 } & $\boldsymbol{a}(\mathbf{M P a})$ & $\boldsymbol{b}$ & $\begin{array}{c}\text { Correlation } \\
\text { factor }\end{array}$ \\
\hline $\boldsymbol{0}$ & 314.3 & -0.1361 & 0.9926 \\
\hline $\mathbf{0 . 2 5}$ & 242.5 & -0.1359 & 0.9858 \\
\hline $\mathbf{0 . 5}$ & 163.2 & -0.133 & 0.9837 \\
\hline $\mathbf{0 . 7 5}$ & 99.88 & -0.1305 & 0.9811 \\
\hline
\end{tabular}

TABLE II.FATIGUE CONSTANTS (A) AND (B) FOR $\left[ \pm 45^{\circ}\right]_{3 \mathrm{~s}}$ SPECIMENS

\begin{tabular}{|c|c|c|c|}
\hline $\begin{array}{c}\text { Pressure ratio } \\
\left(\boldsymbol{P}_{\boldsymbol{r}}\right)\end{array}$ & \multicolumn{3}{|c|}{$\left[ \pm \mathbf{4 5} \boldsymbol{\%}_{\mathbf{3}}\right.$} \\
\cline { 2 - 4 } & $\boldsymbol{a}(\mathbf{M P a})$ & $\boldsymbol{b}$ & $\begin{array}{c}\text { Correlation } \\
\text { factor }\end{array}$ \\
\hline $\boldsymbol{0}$ & 226.6 & -0.1284 & 0.9953 \\
\hline $\mathbf{0 . 2 5}$ & 169.7 & -0.1264 & 0.9876 \\
\hline $\mathbf{0 . 5}$ & 107.5 & -0.1218 & 0.9845 \\
\hline $\mathbf{0 . 7 5}$ & 62.09 & -0.1181 & 0.9803 \\
\hline
\end{tabular}

IV. NEURAL NETWORK TO STUDY THE EFFECT OF STRESS RATIO

An ANN is designed to predict the fatigue life of glass fiber reinforcement epoxy (GFRE) with the maximum bending stress $\sigma_{\max }$ and pressure ratio $P_{r}$, as the input and the number of cycles to failure $N$ is the output. Two neural network structures, feed forward 
FFNN and generalized regression GRNN, are applied, trained and tested.

\section{A. A feed-forward Neural Network FFNN}

A feed-forward $\mathrm{NN}$ with the structure is applied for training the data of $\left[0,90^{\circ}\right]_{3 \mathrm{~s}}$ and $\left[ \pm 45^{\circ}\right]_{3 s}$ fiber orientations at different pressure ratios $\left(P_{r}\right)$. Fig.1 shows the training performance of suggested feedforward NN. Fig.2 and Fig.3 represent the comparison between the experimental data and the feed forward neural network $F F N N$ predicted number of cycles to failure at $\left(\mathrm{P}_{\mathrm{r}}=0,0.25,0.5\right)$ for both fiber orientations. The results of this case show much satisfactory predication quality for this case study. Fig. 4 and Fig.5 shows the comparison between the experimental data and the feed forward neural network $F F N N$ expected data at $\left(P_{r}=0.75\right)$. From these Figures, it noted that the expected data from the suggested feed forward neural network FFNN are applicable with the experimental data.

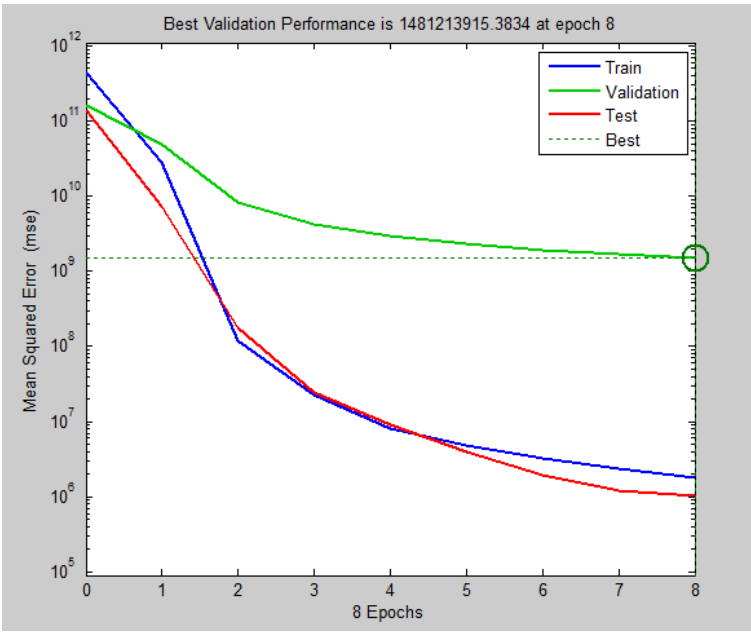

Figure 1.Training performance of suggested feed-forward NN

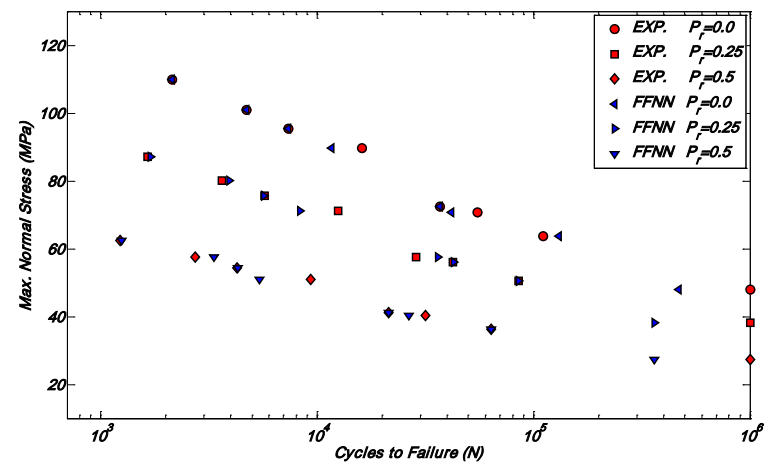

Figure 2.Comparison between the experimental data and the feed forward neural network FFNN predicted data for $\left[0,90^{\circ}\right]_{3 \mathrm{~s}}$ specimens withP $\mathrm{P}_{\mathrm{r}}=0,0.25,0.5$

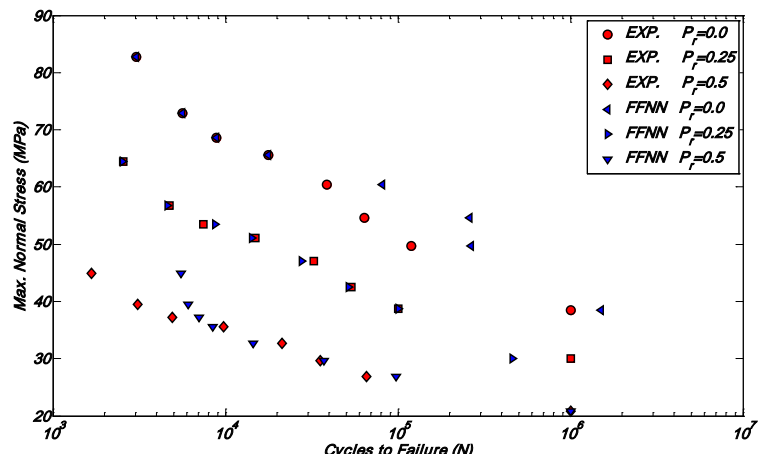

Figure 3.Comparison between the experimental data and the feed forward neural network FFNN predicted data for $\left[{ }^{2} 45^{\circ}\right]_{3 \mathrm{~s}}$ specimens with $\mathrm{P}_{\mathrm{r}}=0,0.25,0.5$

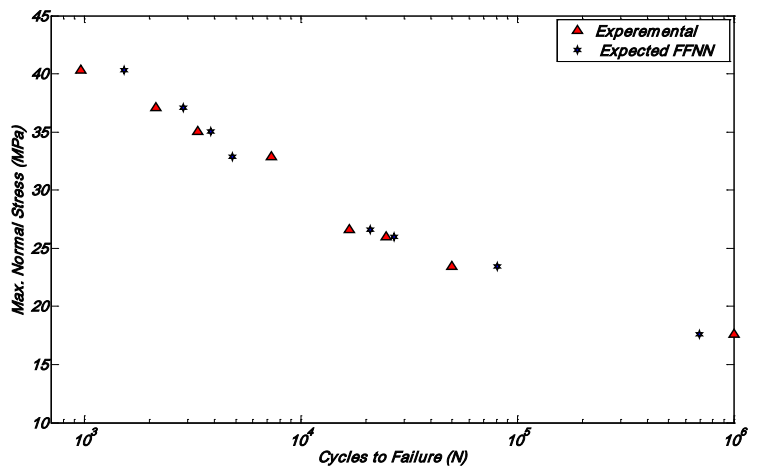

Figure 4.Comparison between the experimental data and the feed forward neural network FFNN Expected data for $\left[0,90^{\circ}\right]_{3 \mathrm{~s}}$ specimens with $\mathrm{P}_{\mathrm{r}}=0.75$

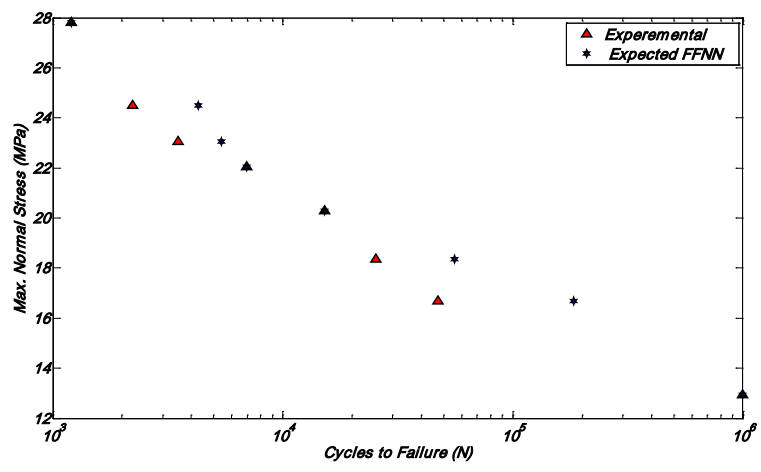

Figure 5.Comparison between the experimental data and the feed forward neural network FFNN Expected data for $\left[{ }^{2} 45^{\circ}\right]_{3 \mathrm{~s}}$ specimens with $\mathrm{P}_{\mathrm{r}}=0.75$

\section{B. Generalized regression Neural Network}

A generalized regression $\mathrm{NN}$ [9] is designed based on two layers, the first, input layer, has radial basis neurons while the second layer has pure linear ones. This network is trained by the measured values of $\sigma_{\max }, P_{r}, \theta$ and $N$. Fig.6 shows the Schematic Illustration of GRNN design for present study with input data $\sigma_{\max }, P_{r}, \theta$ and $N$. 
Fig.7 and Fig.8 represent the comparison between the experimental data and the generalized regression neural network GRNN predicted number of cycles to failure at $\left(P_{r}=0,0.25,0.5\right)$ for both fiber orientation. The results show much better predication quality for the case of $\left[ \pm 45^{\circ}\right]_{3 s}$ than $\left[0,90^{\circ}\right]_{3 \mathrm{~s}}$ and, which represents the same conclusions found when using feed-forward $\mathrm{NN}$ discussed earlier. One can see that the time needed in the present net is much smaller than the CPU time found in feed-forward NN.

Fig.9 and Fig.10 shows the comparison between the experimental data and the generalized regression neural network $G R N N$ expected data at $\left(P_{r}=0.75\right)$.

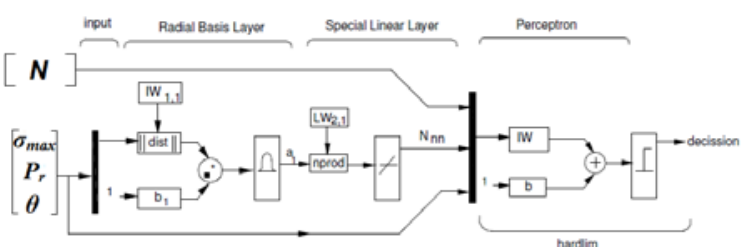

Figure 6.Schematic Illustration of GRNN design for present study with input data $\sigma_{\max }, \mathrm{P}_{\mathrm{r}}, \theta$ and $\mathrm{N}$

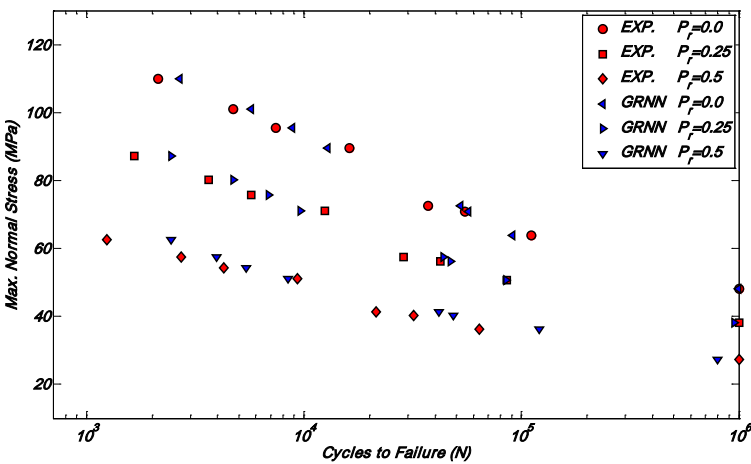

Figure 7.Comparison between the experimental data and the generalized regression neural network GRNN predicted data for $\left[0,90^{\circ}\right]_{3 \mathrm{~s}}$ specimens with $\mathrm{P}_{\mathrm{r}}=0,0.25,0.5$

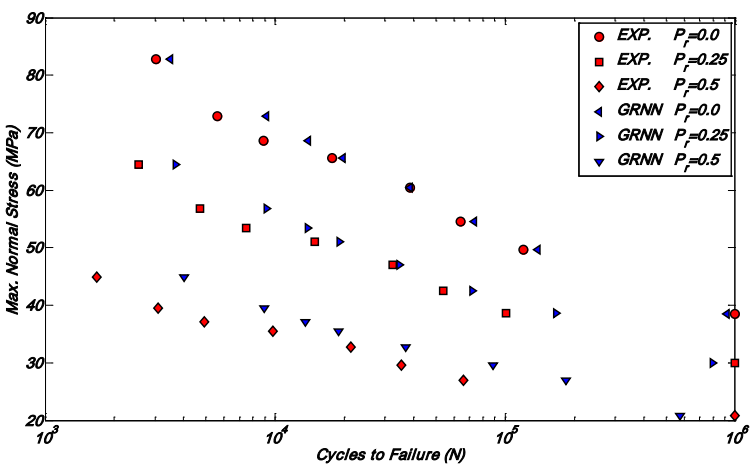

Figure 8.Comparison between the experimental data and the generalized regression neural network GRNN predicted data for $\left[ \pm 45^{\circ}\right]_{3 \mathrm{~s}}$ specimens withP $\mathrm{P}_{\mathrm{r}}=0,0.25,0.5$

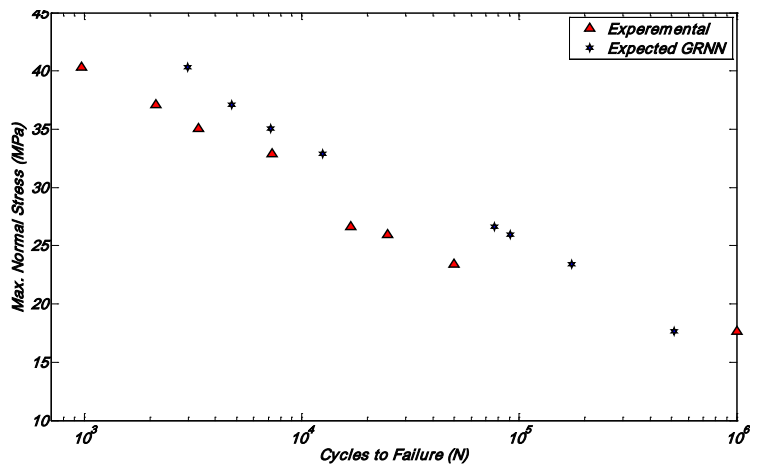

Figure 9.Comparison between the experimental data and the generalized regression neural network GRNN Expected data for $\left[0,90^{\circ}\right]_{3 \mathrm{~s}}$ specimens with $\mathrm{P}_{\mathrm{r}}=0.75$

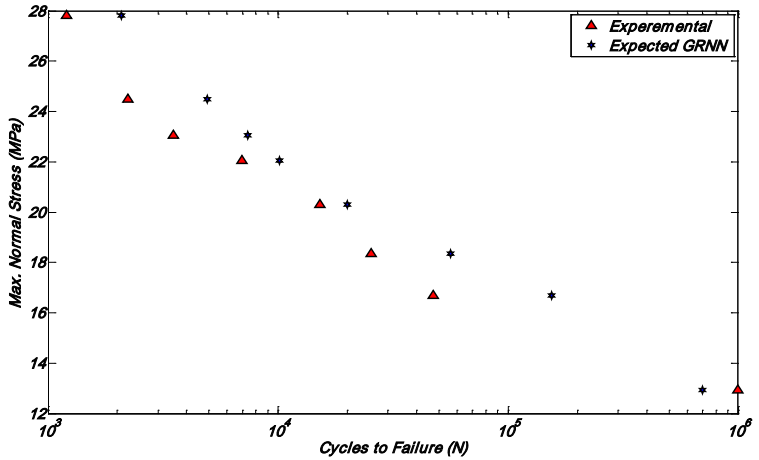

Figure 10.Comparison between the experimental data and the generalized regression neural network GRNN Expected data for $\left[ \pm 45^{\circ}\right]_{3 \mathrm{~s}}$ specimens with $\mathrm{P}_{\mathrm{r}}=0.75$

\section{EXPERT SYSTEM DESIGN}

It is very useful from the designer point of view to have an expert system aids to decide whether his suggested design for composite structure is suitable or not. A NN system is designed to consider the maximum stress, pressure ratio $\mathrm{P}_{\mathrm{r}}$ and the number of cycles to failure $\mathrm{N}$ needed, as inputs and to get yes or no as output.

Table (3) and Table (4) gives the values of mean square error (MSE), mean absolute relative error $N_{z}$, and CPU time in seconds (see Equations 2 and 3) between the expected and experimental data for both networks in order to compare between the performances of two networks.

The performances of two networks data in Table (3) and Table (4) were drawn in Fig.11 for easily comparison.

$$
\begin{aligned}
& M S E=\frac{\sum\left(N_{n n}-N\right)^{2}}{n} \\
& N_{z}=\sum_{1}^{n}\left(\frac{A B S\left(N_{n n}-N\right)}{n N}\right)
\end{aligned}
$$


Where:

$\mathrm{N}_{\mathrm{nn}}$ is the predicted number of cycles to failure,

$N$ is the number of cycles to failure measured from experimental work,

$n$ is the number of experimentally measured data values,

$A B S$ is the absolute value.

TABLE III: (MSE), $\mathrm{N}_{\mathrm{z}}$, AND CPU TIME FOR FFNN AT $\mathrm{P}_{\mathrm{R}}=0.75$

\begin{tabular}{|c|c|c|c|}
\hline \multirow{2}{*}{$\begin{array}{c}\text { Fiber } \\
\text { orientation }\end{array}$} & \multicolumn{3}{|c|}{ FFNN } \\
\cline { 2 - 4 } & $\boldsymbol{M S E}$ & $\boldsymbol{N}_{\boldsymbol{z}}$ & $\begin{array}{c}\boldsymbol{C P U} \\
\text { time (s) }\end{array}$ \\
\hline$[\mathbf{0 , 9 0}]_{\mathbf{3 s}}$ & $1.96 E 8$ & 0.18 & 520 \\
\hline$[ \pm \mathbf{4 5}]_{\mathbf{3 s}}$ & $3.56 E 8$ & 0.17 & 342 \\
\hline
\end{tabular}

TABLE IV: (MSE), NZ, AND CPU TIME FOR GRNN AT $\mathrm{P}_{\mathrm{R}}=0.75$

\begin{tabular}{|c|c|c|c|}
\hline \multirow{2}{*}{$\begin{array}{c}\text { Fiber } \\
\text { orientation }\end{array}$} & \multicolumn{3}{|c|}{ GRNN (Spread factor=1.0) } \\
\cline { 2 - 4 } & $\boldsymbol{M S E}$ & $\boldsymbol{N}_{z}$ & CPU time (s) \\
\hline$[\mathbf{0 , 9 0}]_{3 s}$ & $2.9 E 6$ & 0.053 & 1.9 \\
\hline$\left[ \pm 45^{\circ}\right]_{3 s}$ & $5.61 E 6$ & 0.046 & 1.6 \\
\hline
\end{tabular}
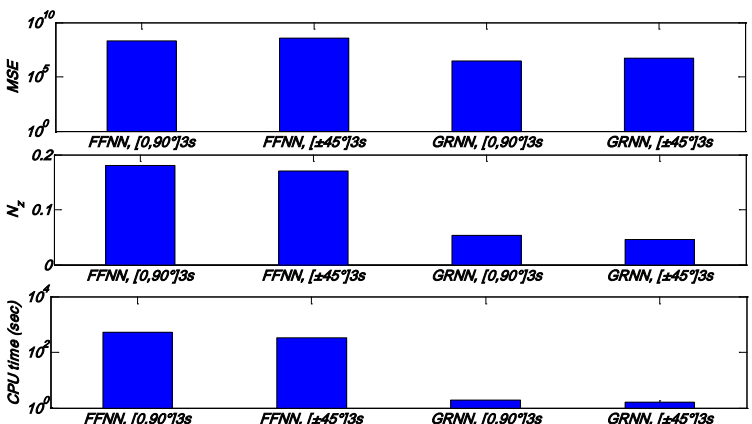

Figure 11.Comparison between FFNN and GRNN Performance data in Table (3) and Table (4)

\section{CONCLUSIONS}

According to the above simulation it $\mathrm{i} s$ concluded that:

1) Both feed forward neural network $F F N N$ and generalized regression neural network $G R N N$ are suitable for life prediction of GFRE.

2) The results show much better predication quality for the case of $\left[ \pm 45^{\circ}\right]_{3 s}$ than $\left[0,90^{\circ}\right]_{3 \mathrm{~s}}$ for both feed forward neural network FFNN and generalized regression neural network GRNN. , Table (3) and Table (4) and Fig. 11.

3) The feed forward neural network $F F N N$ is more suitable than generalized regression neural network GRNN for representing case study of GFRE, Table (3) and Table (4) and Fig.11.

\section{REFERENCES}

[1] R. Talerja, Fatigue of Composite Material, Tech. Pub. Co. Inc., Basel (1987).

[2] J.A. Lee, D.P. Almond and B. Harris The Use of Neural Networks for the Predication of Fatigue Lives of Composite Materials, Composites Part A: Applied Science and Manufacturing, Vol. 30 (10), pp. 11591169 (1999).

[3] F. Aymerich and M. Serra, Predication of Fatigue Strength of composite Laminates by Means of Neural Networks, Key Engineering Materials, Vol. 144, pp. 231- 240 (1998)

[4] Y. Al-Assaf and H. El-Kadi, Fatigue Life Predication of Unidirectional Glass fiber/ Epoxy Composite Laminate Using Neural Networks, Composite Structures, Vol. 53 (1), pp. 65-71 (2001).

[5] H. El-Kadi and Y. Al-Assaf, Predication of the Fatigue Life of Unidirectional Glass fiber/ Epoxy Composite Laminate Using different Neural Networks Paradigms, Composite Structures, Vol. 55, pp. 239- 246 (2002).

[6] H. El-Kadi and Y. Al-Assaf Energy-Based Fatigue Life Predication of fiber Glass /Epoxy Composites Using Modular Neural Networks, Composite Structures, Vol. 57, (1-4), pp. 85-89 (2002).

[7] S.W. Choi, Song Eung-Jung and H.T. Hahn, Predication of Fatigue Damage Growth in Notched Composite Laminates Using an Artificial Neural Network, Composite Science and Technology, Vol. 63, (5), pp. 661-665 (2003).

[8] M.N. Abouelwafa, H. El-Gamal, Y. S. Mohammed. and W. A. Al-Tabey, The Effect of Hoop Stress on The Fatigue Behavior of Woven-roving GFRE Closed end Thick Tube Subjected to Combined Bending Moments and Internal hydrostatic Pressure, In Press.

[9] Conle and J. Ingall Effects of Mean Stress on the Fatigue of Composite Materials, J. of Composites Technology and Research, Vol. 7 (1), pp. 3-11 (1985).

[10] H. Demuth and M. Beale, Neural Network Toolbox User's Guide for use with MATLAB Version 4.0, The Math Works, Inc. (2000).

\section{Creative Commons Attribution License 4.0 (Attribution 4.0 International, CC BY 4.0)}

This article is published under the terms of the Creative Commons Attribution License 4.0 https://creativecommons.org/licenses/by/4.0/deed.en US 